\title{
RELAÇÕES ENTRE IDADE CRONOLÓGICA, COMPRIMENTO TRONCO-CEFÁLICO, COMPRIMENTO DE MEMBROS INFERIORES E MATURAÇÃO SEXUAL EM ESCOLARES DE 10 A 19 ANOS.*
}

\author{
Raymond Victor Hegg ** \\ Emédio Bonjardim ${ }^{\star \star *}$
}

\section{Resumo}

São estudadas as variaçōes dos dois segmentos em função da maturação sexual avaliada através do volume testicular. Numa pesquisa sobre crescimento e desenvolvimento, com a participação dos autores, em 1978, foram medidos e avaliados 3.416 escolares masculinos de 10 a 19 anos, representando uma amostra estratificada da população de Santo André - Grande São Paulo. Foram obtidos peso, estatura, comprimento tronco-cefálico, comprimento dos membros inferiores (diferença entre estatura e comprimento tronco-cefálico), diâmetros biacromial e bicrista-iliaca, dobras cutâneas tricipital, subescapular, supra crista-iliaca e abdominal: a puberdade também toi avaliada através do desenvolvimento piloso pubiano, desenvolvimento dos genitais e volume testicular, este último mediante uso do orquidómetro de Prader.

\section{Introdução}

A estatura de qualquer indivíduo pode ser decomposta em dois segmentos: comprimento tronco-cefálico e comprimento de membros inferiores leste obtido por diferença entre os valores da estatura e do comprimento tronco-cefálico).

$O$ desenvolvimento destes dois segmentos sofre uma influência da puberdade como já afirmou Godin (1935) e entre outros autores, Pineau (1963).

Entendemos ser interessante estudarmos as relaçōes entre o desenvolvimento destes dois
São somente analisadas as variaçōes do comprimento tronco-cefálica e comprimento dos membros inferiores correlacionadas com volume testicular classificando-se os escolares em três grupos: pré-püberes (416) com volumes $1-2-3$, púberes (1063) com volumes $4-5-6$ - 8 - 10 - 12, e pós-púberes (1937) com volumes 15 20 - 25. A análise de variância efetuada mostrou haver diferença siginificante a nivel de 0.05 entre os grupos para os valores de cada variável antropométrica; o teste de Scheffé mostrou haver diferenca significante a nivel de 0.05 entre os grupos pré-puibere e pubere, $e$ entre os grupos pubere e pós-púbere para os valores de cada variável antropométrica. Conclue-se que a maturaçāo sexual é responsável pelas variaçōes entre os valores do comprimento tronco-cefálico e do comprimento dos membros inferiores.

segmentos e uma variável de maturação sexual representada pelo volume testicular esquerdo.

\section{Metodologia}

Numa pesquisa sobre crescimento e desenvolvimento realizada em 1978 e da qual participamos, cuja metodologia baseou-se no estudo de Marcondes et alii (1982) onde se encontra descrita na íntegra, foram medidos e avaliados 6.794 escolares (3416 do sexo masculino e 3378 do sexo feminino) de 10 a 19 anos, representando uma amostra estratificada da população escolar de

\footnotetext{
Resumo do trabalho apresentado no "Olympic Scientific Congress, july 19-26, Eugene, Oregon, USA"

** Professor Emérito da EEF-USP

*** Professor Assistente da disciplina de Handebol, da EEF-USP
} 
Santo André Grande São Paulo. Obtivemos peso, estatura, comprimento tronco-cefálico, comprimento de membros inferiores (diferença entre estatura e comprimento tronco-cefálico), diâmetros bi-acromial e bi-cristailíaca, dobras cutâneas tricipital, supra-escapular, supra-iliaca e abdominal em ambos os sexos. Avaliamos também a puberdade no sexo masculino através do desenvolvimento da pilosidade pubiana, dos genitais e volume testicular, este através do orquidômetro de Prader (1966) e desenvolvimento da pilosidade pubiana, das mamas e data do aparecimento da menarca no sexo feminino.

Neste trabalho analisamos exclusivamente as variaçōes e as relaçōes entre idade cronológica, comprimento tronco-cefálico e comprimento de membros inferiores e a maturação sexual nos escolares do sexo masculino de 10 a 19 anos, esta avaliada através de volume testicular esquerdo obtido pela palpação comparando-se com os padrões fornecidos pelo orquidômetro de Prader (1966).

Classificamos os escolares em 3 grupos, segundo Sempé et alii, a saber: pré-púberes (416) com volumes 1, 2, 3; púberes (1063) com volumes $4,5,6,8,10,12$ e pós-púberes (1937) com volumes 15, 20, 25.

As medidas foram analisadas em termos de média aritmética e desvio padrāo e são apresentadas nas tabelas 1 e 2. O T test foi utilizado para amostras independentes a nivel de .05 para comparar o desenvolvimento de cada variável antropométrica em função de estágios pubertários pré- púbere, púbere e pós-púbere. A análise de variância e teste de Scheffé foram também utilizados para situar a significância entre os vários grupos para cada variável antropométrica em função da idade.

\section{Resultados}

Os resultados são representados nas tabelas 1 e 2.

As tabelas 1 e 2 apresentam aos 10 e 11 anos, no grupo pós-púbere, apenas 1 e 2 indivíduos respectivamente. Aos 15 e 18 anos, no grupo pré-púbere, aparece apenas 1 individuo em cada faixa etária. Aos 16, 17 e 19 anos, nesse mesmo grupo, não há indivíduo.

\section{Discussāo}

$\mathrm{Na}$ análise dos resultados as caselas com apenas 1 ou 2 individuos foram. desprezadas.

Constatamos que no grupo pré-púbere o comprimento tronco-cefálico aumentou em média $3,01 \mathrm{~cm}$, no grupo púbere o aumento médio foi de $14,80 \mathrm{~cm}$ e no grupo pós-púbere foi de $6,94 \mathrm{~cm}$.

Com relação ao comprimento dos membros inferiores notamos no grupo pré-púbere um aumento médio de $7,84 \mathrm{~cm}$, no grupo púbere o aumento médio foi de $15,63 \mathrm{~cm}$ e no grupo pós-púbere foi de $4,34 \mathrm{~cm}$.

Tabela 1 Variações do comprimento tronco-cefálico em função de idade e estágios pubertários.

\begin{tabular}{c|c|c|c|c|c|c|c|c|c}
\hline \multirow{3}{*}{ Idade } & \multicolumn{3}{|c|}{$\begin{array}{c}\text { Volume Testicular } \\
1,2 \text { e 3 }\end{array}$} & \multicolumn{3}{c|}{$\begin{array}{c}\text { Volume Testicular } \\
4,5,6,8,10 \text { e 12 }\end{array}$} & \multicolumn{3}{c}{$\begin{array}{c}\text { Volume Testicular } \\
15,20 \text { e 25 }\end{array}$} \\
\cline { 2 - 10 } & $\mathrm{N}$ & $\mathrm{x}$ & $\mathrm{dp}$ & $\mathrm{N}$ & $\mathrm{x}$ & $\mathrm{dp}$ & $\mathrm{N}$ & $\mathrm{x}$ & $\mathrm{dp}$ \\
\hline 10 & 131 & 71,85 & 3,26 & 33 & 74,54 & 2,84 & 01 & 75,00 & \\
11 & 113 & 73,81 & 3,16 & 71 & 76,65 & 3,55 & 02 & 89,20 & 7,35 \\
12 & 123 & 75,38 & 3,39 & 243 & 77,95 & 3,92 & 20 & 83,69 & 5,07 \\
13 & 39 & 75,26 & 3,31 & 269 & 78,62 & 4,06 & 100 & 84,70 & 6,02 \\
14 & 08 & 74,86 & 4,04 & 224 & 81,07 & 4,62 & 195 & 86,33 & 4,17 \\
15 & 01 & 73,60 & & 108 & 82,59 & 5,30 & 283 & 88,20 & 5,76 \\
16 & 00 & & & 43 & 84,64 & 4,74 & 337 & 89,50 & 4,77 \\
17 & 00 & & & 38 & 87,36 & 4,55 & 332 & 90,29 & 3,62 \\
18 & 01 & 81,70 & & 17 & 87,42 & 2,93 & 359 & 90,51 & 3,65 \\
19 & 00 & & & 17 & 89,34 & 3,60 & 308 & 90,63 & 5,21 \\
\hline & 416 & 73,83 & & 1063 & 79,99 & & 1937 & 89,18 & \\
\hline
\end{tabular}


Tabela 2 - Variações do comprimento de membros inferiores em função da idade e estágios pubertários.

\begin{tabular}{c|c|c|c|c|c|c|c|c|c}
\hline \multirow{3}{*}{ Idade } & \multicolumn{3}{|c|}{$\begin{array}{c}\text { Volume Testicular } \\
1,2 \text { e 3 }\end{array}$} & \multicolumn{3}{c|}{$\begin{array}{c}\text { Volume Testicular } \\
4,5,6,8,10 \text { e 12 }\end{array}$} & \multicolumn{3}{c}{$\begin{array}{c}\text { Volume Testicular } \\
15,20 \text { e 25 }\end{array}$} \\
\cline { 2 - 10 } & $\mathrm{N}$ & $\mathrm{x}$ & $\mathrm{dp}$ & $\mathrm{N}$ & $\mathrm{x}$ & $\mathrm{dp}$ & $\mathrm{N}$ & $\mathrm{x}$ & $\mathrm{dp}$ \\
\hline 10 & 131 & 63,98 & 3,43 & 33 & 65,81 & 4,46 & 01 & 68,70 & \\
11 & 113 & 66,81 & 3,63 & 71 & 70,41 & 3,56 & 02 & 80,50 & 0,28 \\
12 & 123 & 68,40 & 4,09 & 243 & 70,93 & 4,37 & 20 & 77,02 & 4,61 \\
13 & 39 & 69,94 & 5,32 & 269 & 73,16 & 4,53 & 100 & 78,51 & 6,86 \\
14 & 08 & 71,82 & 7,97 & 224 & 75,33 & 4,94 & 195 & 78,68 & 4,56 \\
15 & 01 & 68,30 & & 108 & 77,87 & 5,66 & 283 & 79,84 & 6,24 \\
16 & 00 & & & 43 & 79,50 & 4,64 & 337 & 81,04 & 5,36 \\
17 & 00 & & & 38 & 80,29 & 4,23 & 332 & 81,60 & 4,59 \\
18 & 01 & 87,90 & & 17 & 79,06 & 5,39 & 359 & 81,42 & 4,79 \\
19 & 00 & & & 17 & 81,47 & 5,85 & 308 & 81,36 & 6,09 \\
\hline & 416 & 66,83 & & 1063 & 73,91 & & 1937 & 80,67 & \\
\hline
\end{tabular}

A análise de variância e o teste de Scheffé mostraram haver diferença significativa a nivel de .05 entre os comprimentos médios dos indivíduos que constituem os grupos pré-púberes (416), púbere (1063) e pós-púbere (1937), assim como entre os grupos púbere (1063) e pós-púbere (1937). afirmativa válida tanto para o comprimento tronco-cefálico como para o comprimento dos membros inferiores.

O T test utilizado nas faixas etárias de 10 e 11 anos mostrou haver diferença significativa a nível de .05 entre os valores dos grupos pré-púberes e púberes para o comprimento tronco-cefálico. O mesmo se verifica nas idades de 15, 16, 17 e 18 anos entre os grupos púberes e pós-púberes, não havendo diferença entre os mesmos grupos aos 19 anos. Aos 12, 13 e 14 anos a análise de variância e o teste de Scheffé mostraram haver diferença significativa a nivel de .05 entre os valores dos grupos pré-púberes, púbere e pós-púbere (tab.1).

Para o comprimento de membros inferiores o T test utilizado nas faixas de 10 e 11 anos mostrou haver diferença significativa a nível de .05 entre os grupos pré-púbere e púbere. 0 mesmo se verifica nas idades de 15 e 18 anos entre os grupos púbere e pós-púbere, não havendo diferença significativa entre os mesmos grupos nas faixas etárias de 16, 17 e 19 anos. Aos 12 e 13 anos a análise de variância e o teste de Scheffé mostraram haver diferença significativa entre os valores dos grupos pré-púbere, púbere e pós-púbere. Aos 14 anos, a mesma análise mostra diferença significativa entre pre-púberes e pós-púberes e entre púberes e pós-púberes, não havendo diferença significativa entre pré-púberes e púberes (tab.2).

\section{Conclusōes}

A diferença entre os comprimentos médios dos três grupos (pré-púbere, púbere e pós-púbere), assim como para os grupos púbere e pós-púbere, para as duas variáveis em estudo, parecenos ser devido a influência da maturação sexual.

Fixando-se uma idade, notamos que há também influência positiva da maturação sexual, de maneira geral, nos valores dos três grupos e nos valores das duas variáveis antropométricas.

Achamos que ao se comparar valores antropométricos em escolares durante a adolescência, deve-se levar em consideração, além da idade cronológica, os estágios de maturação sexual, pois estes fornecem informaçōes válidas sobre idade fisiológica. 
Study the varic: ": of the two seqments related to sexual maturation evaluated through the testis development. In a research about growth and development from wich we have participated in 1978 were measured and evaluated 3.416 male students from 10 to 19 years, representing and stratified sample of the studving population from Santo André - Grande São Paulo. We have obtained weight, standing height, sitting height. lenght of lower limbs (difference hetween stanting height and sitting height). biacromial and bitliac diameters, triceps, subescapular, suprailiac and abdominal skinfolds: we have also evaluated the puberty through development of pubic hair, development of genitalla and testis size. the last trough the Prader orchidometer. We have tried of lower limbs through the testis size. classifying the students in three groups: prepubescents (416) with sizes $1-2-3$, pubescents (1063) with sizes $4-5-6-8-10-12$, and pos-pubescents (1937) with sizes $15-20-25$. The variance analises pertormed showed that there was a significant difference at the level of 0.05 among the groups for the values of each anthropometric variant, the scheffe test showed that there was significant difference at the tevel. 0,05 between the pre-pubescent and the pubescent groups and between the puboscent and the pospubescent groups for the values of each anthropomeInc variant It was concluded that the sexual maturation is responsible for the variation between the values of the sitting height and the lenght of lower limbs

\section{REFERËNCIAS BIBLIOGRÁFICAS}

GODIN P. Recherches anthropométriques sur la croissance des diverses parties du corps. 2 ed. Paris, Amedẻe Legrand, 1935.

MARCONDES E. et alii. Crescimento e desenvolvimento pubertário em crianças e adolescentes brasileiros. São Paulo, Ed. Bras. Cienc., 1982. v.1.
PINEAU M. Corelations du stage pubertaire et de l'age avec les caracteres anthropometriques chèz dez garçons. Biotypologie. 1-2, 1963.

PRADER, A. O tamanho dos testiculos: avaliaçāo e importância clínica. Triângulo. 7:240-243, 1966.

SEMPÉ, M. et alii. Auxologie: métode et sequences. Paris, Laboratorie Thereplix, 1979. 